\title{
Bilateral Wilms tumor with neonatal onset and the importance of prenatal diagnosis
}

\author{
Giuseppe De Bernardo ${ }^{1 *}$, Angela Lucariello ${ }^{2 \&}$, Antonio Saggese ${ }^{3}$, Maurizio Giordano ${ }^{1}$, Desiree Sordino ${ }^{1}$, \\ Carmela Buonomo $^{4}$, Stefano Gisone ${ }^{5}$, Antonio De Luca ${ }^{5}$, Germano Guerra $^{6}$, Angelica Perna ${ }^{6 *}$ \\ ${ }^{1}$ Department of Mother's and Child's Health - Fondazione Poliambulanza Istituto Ospedaliero Brescia, Italy \\ ${ }^{2}$ Department of Sport Sciences and Wellness, University of Naples "Parthenope", Naples, Italy \\ ${ }^{3}$ Institute of Legal Medicine, University of Campania "Luigi Vanvitelli", Naples, Italy \\ ${ }^{4}$ UOC Pathological Anatomy A.O.R.N. Sant'Anna-San Sebastiano, Caserta, Italy \\ ${ }^{5}$ Department of Mental Health and Preventive Medicine, section of Human Anatomy, University of Campania "L. Vanvitelli” Naples, Italy \\ ${ }^{6}$ Department of Medicine and Health Sciences "Vincenzo Tiberio", University of Molise, Campobasso, Italy
}

\section{A R T I C L E I N F O}

Article Type:

Case Rep0rt

Article History:

Received: 23 July 2019

Accepted: 20 August 2019

Published online: 13 September 2019

Keywords:

Case report

Ultrasonography

Hypovolemic shock

Kidney tumor

\begin{abstract}
A B S T R A C T
Wilms tumor (WT) occurs in 1:10.000 live births and affects mainly the unilateral kidney. The National Wilms Tumor Study Group registered 6832 patients with WT from 1969 to January 1993, out of whom only 11 patients $(0.16 \%)$ were newborns. Since 1969,14 cases of prenatal diagnosis of WT have been reported in literature, two of which were bilateral WT. Currently, the patients' survival rate is greater than $90 \%$, owing to a combination of surgery, chemotherapy, and radiotherapy for high-risk patients.

We report a case of bilateral WT, undiagnosed during the prenatal period due to the incomplete evaluation of the abdomen with ultrasonography. The newborn was vaginally delivered at 40 weeks' gestational age with a good perinatal adaptation. Suddenly, during the night the newborn showed respiratory distress, bradycardia and then respiratory arrest. For this reason, he was ventilated, intubated and subjected to conventional mechanical ventilation. Despite the normal cardiac ultrasonography, the health care providers suspected a cyanotic congenital heart disease with duct dependency. After a gradual resumption of the oximetry and blood pressure, the infant was transported by the neonatal emergency transport system to the Cardiac Pediatric Surgery Department of a level III hospital. There, the clinical condition became extremely serious and the infant died of asystole. During autopsy, two large tumoral masses were found in both kidneys, also the characterization of the tumors was done through histological exam, which confirmed the diagnosis of WT. A prenatal diagnosis of WT is very important because the families can take advantage of prenatal counseling to understand the risks of continuing the pregnancy and to evaluate the need for abortion, while health care providers can prepare to face a difficult delivery. The review of the literature suggests that prenatal diagnosis of bilateral WT is possible. During prenatal age, the complete assessment of the abdomen with ultrasonography and Eco-Color-Doppler can reveal kidney anomalies and raise suspicion of diseases with urinary malformations.
\end{abstract}

Implication for health policy/practice/research/medical education:

Diagnosis of Wilms Tumor can be obtained by fetal ultrasonography.

Please cite this paper as: De Bernardo G, Lucariello A, Saggese A, Giordano M, Sordino D, Buonomo C, et al. Bilateral Wilms tumor with neonatal onset and the importance of prenatal diagnosis. J Renal Inj Prev. 2019;8(4):257-262. DOI: 10.15171/ jrip.2019.49.

\section{Introduction}

Wilms tumor (WT) is an embryonal malignancy of the kidney which occurs in 1:10.000 live births, generally affecting a single kidney, however, cases of synchronous bilateral or multifocal tumors are known to occur in $10 \%$ of patients $(1,2)$. Although the disease can be diagnosed at any age, WT most prevalently affects children between 1-5 years old; in $15 \%$ of cases, it is diagnosed before the first year of life and only $2 \%$ of cases involve children aged over 8 years $(2)$.

\footnotetext{
*Corresponding authors: Giuseppe De Bernardo, Email: pinodebtin@gmail.com; Angelica Perna, Email: angelica.perna@unimol.it

\& The two authors equally contributed
} 
The National Wilms Tumor Study Group registered 6832 patients with WT from 1969 to January 1993, out of whom only 11 patients $(0.16 \%)$ were newborns (3). Bilateral WT is most frequently diagnosed and recorded in patients aged between 30-33 months, with only 2 cases presenting during the prenatal period $(2,4,5)$.

The cause of this disease is considered heritable in $10 \%$ $15 \%$ of individuals and may be associated with syndromic causes such as WAGR syndrome, Denys-Drash syndrome, Frasier syndrome, and genitourinary anomalies without renal failure. Among patients with WT, approximately $1 \%-2 \%$ have at least one parent with the same pathology. Families with many cases of WT have been studied in details, and the results indicate that this predisposition is due to an autosomal dominant pathogenic variant with incomplete penetrance (2).

In general, a higher frequency of bilateral tumors and an earlier age at diagnosis are observed in families with WT. Recently, the Children's Oncology Group reviewed the five stages of WT defined by the National Wilms Tumor Study Group, as summarized in Table 1 (2).

Currently, the patient survival rate is greater than $90 \%$, owing to a combination of surgery and chemotherapy, in addition to radiotherapy for high-risk patients $(1,2)$. Prenatal diagnosis is fundamental to enable better management of the newborns with WT. We here report a rare case of WT that began dramatically and prematurely in the first hours of life. The disease was not evident upon prenatal tests, owing to the fact that the abdomen had not been carefully evaluated, and the health care providers were therefore unable to manage the newborn's critical condition, despite cardiac reanimation, his condition became irreversible and he subsequently died. Autopsy revealed two great masses in the bilateral kidneys, and histological examination detected WT stage V.

\section{Case Presentation}

A newborn male was vaginally delivered at 40 weeks' gestational age. During the pregnancy, fetal ultrasound was performed, without assessment of the neonatal abdomen and renal conditions. Upon delivery, his airways were aspirated and he was ventilated (fraction of inspired oxygen, 0.30 ) for 15 seconds and stimulated. The body weight was $3350 \mathrm{~g}$, head circumference was $32.5 \mathrm{~cm}$, and length was $51 \mathrm{~cm}$. His Apgar scores were $7^{\mathrm{I}}$ and $8^{\mathrm{V}}$, while blood gas analysis from the umbilical artery revealed the following: $\mathrm{pH}=7.08$, base excess $=-11.5$, hematocrit ; $41.7 \%$ and glucose ; $66 \mathrm{mg} / \mathrm{dL}$. The perinatal adaptation of the newborn was normal and his pulse oximetry was monitored continuously. Abdominal examination was normal. During the night, the newborn suddenly showed respiratory distress $\left(\mathrm{SpO}_{2}=45 \%\right)$ with bradycardia $(<100$ bpm) until respiratory arrest occurred. Consequently, he was ventilated, intubated, and started on conventional mechanical ventilation. Dopamine and dobutamine were administered at a dose of $5 \mu \mathrm{kg} / \mathrm{min}$ and subsequently at 10 $\gamma / \mathrm{kg} / \mathrm{min}$ due to hypotension (40/20 mm Hg). Moreover, he was administered sodium bicarbonate due to metabolic acidosis $(\mathrm{pH}=7.1$, base excess $=-18$ and bicarbonate $=$ $5.2 \mathrm{mmol} / \mathrm{L}$ ), $10 \mathrm{~mL} / \mathrm{kg}$ of fluid bolus of sodium chloride $0.9 \%$, and a transfusion of $10 \mathrm{~mL} / \mathrm{kg}$ of packed $0 \mathrm{Rh}^{-}$red blood cells, owing to a hematocrit level of $25 \%$, along with antibiotic therapy. Despite the normal cardiac ultrasonography, the health care providers suspected a cyanotic congenital heart disease with duct dependency; accordingly, prostaglandin $0.1 \mathrm{~g} / \mathrm{kg} / \mathrm{min}$ was administered to the newborn. Hypotension of $45 / 40 \mathrm{~mm} \mathrm{Hg}$ persisted despite adequate water and the administration of 0.45 $\mathrm{g} / \mathrm{kg} / \mathrm{min}$ of noradrenaline. After these procedures, the neonate showed a gradual resumption of the oximetry $\left(\mathrm{SpO}_{2}=88 \%\right)$ and blood pressure $(47 / 42 \mathrm{~mm} \mathrm{Hg})$ values. Signs of hyperkalemia were also found, and insulin was given to the infant at a dose of $0.1 \mathrm{UI} / \mathrm{kg} / \mathrm{h}$, along with $5 \%$ glucose. He was transported by the neonatal emergency transport system while on mechanical ventilation (fraction of inspired oxygen $=0.70$, peak inspiratory pressure $=20$ $\mathrm{cmH}_{2} \mathrm{O}$, positive end-expiratory pressure $=5 \mathrm{cmH}_{2} \mathrm{O}$, respiratory rate $=40 \mathrm{bpm}$ ) to the Cardiac Pediatric Surgery Department of a level III hospital. There, his condition further worsened, since his blood pressure was undetectable but no cardiac complications were revealed. Thirty minutes after the arrival to the Cardiac Pediatric Surgery Department, as the infant was undergoing cardiac ultrasonography, which confirmed the absence of heart disease, his clinical condition became extremely serious and the infant died of asystole.

During autopsy, microscopic examination showed two large tumoral masses located in both kidneys. The

Table 1. Stages of Wilms tumor reviewed by Children's Oncology Group

\begin{tabular}{|c|c|}
\hline Stage & Description \\
\hline I & $\begin{array}{l}\text { The tumor is limited to the kidney and can be completely excised. There is no penetration of the renal capsule or involvement of the renal } \\
\text { sinus vessels }\end{array}$ \\
\hline II & $\begin{array}{l}\text { The tumor is extending beyond the kidney but can be completely excised. No residual tumor is apparent at or beyond the margins of } \\
\text { excision }\end{array}$ \\
\hline III & $\begin{array}{l}\text { Gross or microscopic residual tumor remaining postoperatively, including inoperable tumors, positive surgical margins, diffuse tumor } \\
\text { spillage or biopsy, regional lymph node metastases, and transacted tumor thrombus }\end{array}$ \\
\hline IV & Hematogenous metastases (lung, liver, bone, brain) or lymph node metastases outside the abdominal and pelvic cavities \\
\hline V & Bilateral renal tumors at diagnosis \\
\hline
\end{tabular}


tumoral masses in the right and left kidneys measured approximately $80 \times 50 \mathrm{~mm}$ and $50 \times 30 \mathrm{~mm}$, respectively. The adrenal glands were affected by parenchymal hemorrhagic necrosis and the cause of death was ascribed to renal artery hemorrhage (Figure 1, A-C).

Characterization of the tumors was done through histological exam, which confirmed the diagnosis of WT with a blastemal pattern focally infiltrating the capsule and tubular structures (cluster of differentiation [CD]56 ${ }^{+}$, chromogranin $\mathrm{A}^{+}, \mathrm{S} 100$, epithelial membrane antigen', pan-cytokeratin', CD99-, transcription termination factor-1, Wilms tumor-1', vimentin', desmin', actin $\mathrm{MS}^{-}$) (Figure 2, A-C).

\section{Discussion}

A prenatal diagnosis of WT is possible, while in most cases, it presents as an asymptomatic abdominal mass. On the other hand, in 20\%-30\% of cases, this disease presents signs and symptoms such as abdominal pain, malaise, microscopic or macroscopic hematuria, and

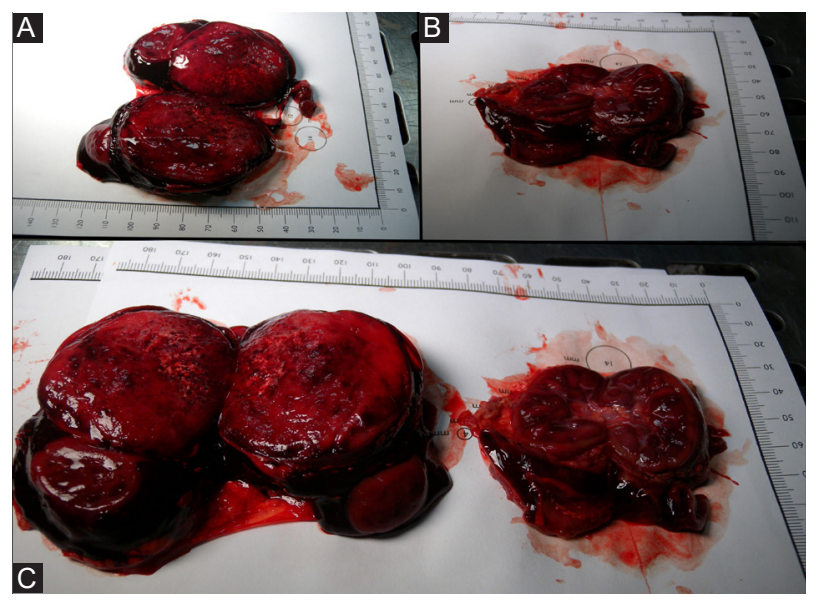

Figure 1. (A, B, C) The bilateral kidneys and adrenal glands showed hemorrhagic parenchymal necrosis. (A) The tumor extended along the entire surface of the right kidney while $(B)$ in the left kidney, there was still visible parenchyma.

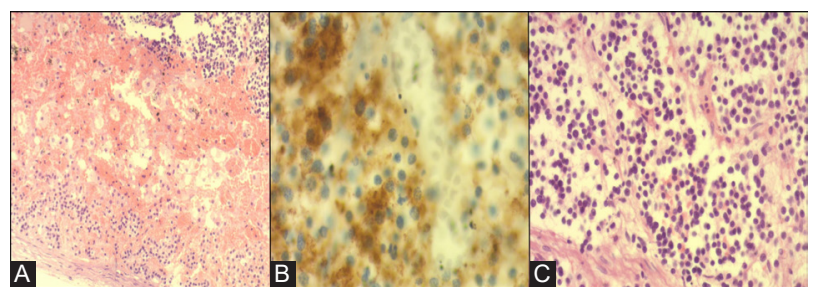

Figure 2. (A) In the lower left figure, the adrenal cortex with hemorrhage can be seen, while in the upper right, proliferation of the Wilms tumor with a blastemal pattern can be observed. Hematoxylin and eosin staining, (light microscopy 10x) (B) Positive immunohistochemical staining for chromogranin A (light microscopy 20x). (C) Blastemal pattern of Wilms tumor with thin segmentations. Hematoxylin and eosin staining, (light microscopy $20 \times$ ). hypertension. Hypertension is considered to develop due to increased renin activity or the presence of a renal mass, however, it resolves after nephrectomy. Tumor extension into the renal vein or inferior vena cava occurs in less than $4 \%$ of cases. In such cases, the symptoms include ascites, congestive cardiac failure, and hepatomegaly (1). To evaluate the presence of a tumor and its potential extension in the contralateral kidney, the initial exam is generally abdominal ultrasonography. However, it can also be identified by genitourinary anomalies, extension of the tumor into the inferior vena cava, and by assessment for liver metastasis (1). We searched all cases of bilateral WT diagnosed during the prenatal period reported on PubMed and compared these with our case. Since 1969, we found only 12 cases of unilateral WT $(3,6-14)$ and 2 cases of bilateral WT $(4,5)$ with a prenatal diagnosis (Table 2 ).

The mean age ( \pm standard deviation) at the prenatal diagnosis was $32.3 \pm 4.1$ gestational weeks (range, 24-37 weeks, excluding cases with unavailable data and gestational ages reported in months). Prenatal ultrasonography revealed the following; left renal mass (36\% of cases), right renal mass ( $29 \%$ of cases), abdominal mass ( $21 \%$ of cases), and multiple renal cysts ( $14 \%$ of cases). Polyhydramnios and fetal hydrops were detected in three cases $(11,12,14)$ and one case had bilateral clubfeet (9). Furthermore, nine infants were diagnosed as WT stage I $(64 \%)(3,6,9-12,14)$, two as stage II $(7,8)$, one as stage III (13) and two as stage $\mathrm{V}(4,5)$. A prenatal diagnosis of WT is very important because the families can take advantage of prenatal counseling to understand the risks of continuing the pregnancy and to evaluate the need for abortion, while health care providers can prepare to face a difficult delivery. In five of the previously reported cases, the surgical operation was performed as soon as possible to avoid rupture of the mass and/or to increase the chance of survival of the infants $(5,6,11,12,14)$. In one case, intrauterine treatment was performed at $28+2$ weeks to decompress the mass of the tumor, however, the surgery failed and the infant died 20 minutes after its preterm birth (12). Delayed surgical operations were performed in three cases; of these, two resulted in a good outcome $(7,8)$ whereas one infant died (13). Elected surgical operations included nephrectomy and nephrourectomy, which showed a survival rate of $42 \%$, and, in five cases, the surgery was supported with chemotherapy $(3,5,7,8,13)$. All patients treated with chemotherapy (vincristine and dactinomycin) survived, except one who did not tolerate the therapy and died due to tumor rupture (13). All infants who showed polyhydramnios and fetal hydrops along with an abdominal mass during the prenatal diagnosis died a few days after birth, despite surgical operation or prenatal intervention $(11,12)$. In general management of WT are complex and required integrated approach (1416). Molecular and innovative therapies are described in literature $(17,18)$. No cases are displayed in literature 
Table 2. Prenatal Diagnoses of Wilms tumor (WT) in the literature

\begin{tabular}{|c|c|c|c|c|c|c|c|c|}
\hline References & $\begin{array}{l}\text { GA at prenatal } \\
\text { diagnosis }\end{array}$ & $\begin{array}{c}\text { Clinical } \\
\text { presentation }\end{array}$ & Pathology & $\begin{array}{c}\text { Age at } \\
\text { intervention }\end{array}$ & Intervention & Chemotherapy & Follow-up & Status \\
\hline Tomà et al (6) & 37 wk & L RM & WT Stage I & 12 days & L NU & None & Unavailable & Alive \\
\hline Ritchey et al (3) & Unavailable & AM & WT Stage I & Unavailable & L NU & None & 16 months & Died \\
\hline Ritchey et al (3) & Unavailable & AM & WT Stage I & Unavailable & R NU & None & 31 months & Alive \\
\hline Ritchey et al (3) & Unavailable & AM & WT Stage I & Unavailable & L NU & $\begin{array}{l}\text { Vincristine, } \\
\text { dactinomycin }\end{array}$ & 41 months & Alive \\
\hline $\begin{array}{l}\text { De Oliveira-Filho et } \\
\text { al (7) }\end{array}$ & Unavailable & L MRC & WT Stage II & 18 months & LN & $\begin{array}{l}\text { Vincristine, } \\
\text { dactinomycin }\end{array}$ & 31 months & Alive \\
\hline Homsy et al (8) & $32 \mathrm{wk}$ & L MRC & WT Stage II & 5 months & LN & $\begin{array}{l}\text { Vincristine, } \\
\text { dactinomycin }\end{array}$ & 6 years & Alive \\
\hline Suresh et al (9) & $37 w k$ & L RM, BLC & WT Stage I & 0 day & Unavailable & None & 0 day & Died \\
\hline Applegate et al (10) & $36 \mathrm{wk}$ & R RM & WT Stage I & Unavailable & R NU & None & Unavailable & Alive \\
\hline Vadeyar et al (11) & $28 w k$ & $\mathrm{P}, \mathrm{FH}, \mathrm{LRM}$ & WT Stage I & 28,29 wks & $\mathrm{RB}$ & None & 0 day & Died \\
\hline Glick et al (12) & 34 wk & $\mathrm{P}, \mathrm{FH}, \mathrm{R} \mathrm{RM}$ & WT Stage I & 0 day & R NU & None & 0 day & Died \\
\hline Cavicchioni et al (4) & 24 wk & R HK & WT Stage V & Unavailable & Abortion & None & 0 day & Died \\
\hline Linam et al (5) & 33 wk & R RM & WT Stage V & 3 days & $\mathrm{R} \mathrm{N}$ & $\begin{array}{l}\text { Vincristine, } \\
\text { dactinomycin }\end{array}$ & 1 year & Alive \\
\hline Jain et al (13) & $7^{\text {th }}$ mon & L RM & WT Stage III & 7 months & L NU & $\begin{array}{c}\text { Vincristine, } \\
\text { actinomycin D, } \\
\text { adriamycin }\end{array}$ & Unavailable & Died \\
\hline Sarin et al (14) & $29,71 \mathrm{wk}$ & P, FH, L RM & WT Stage I & 4 days & L NU & None & 6 days & Died \\
\hline
\end{tabular}

$\mathrm{RM}=$ renal mass; $\mathrm{AM}=$ abdominal mass; $\mathrm{L} \mathrm{MRC}=$ left multiple renal cysts; $\mathrm{BLC}=$ bilateral clubfeet; $\mathrm{P}=$ polyhydramnios; $\mathrm{FH}=\mathrm{fetal}$ hydrops; $\mathrm{L} \mathrm{RM}=\mathrm{left}$ renal mass; $\mathrm{HK}=$ hyperechoic kidney; $\mathrm{L} N=$ left nephrectomy; $\mathrm{R} \mathrm{NU=right} \mathrm{nephrourectomy;} \mathrm{L} \mathrm{NU}=$ left nephrourectomy; $\mathrm{RB}=$ renal biopsy.

about cell based therapy $\mathrm{Ca}^{2+}$ toolkit targets mediated as described in neonatal and adult tumors including renal carcinoma (19-29). As mentioned above, in the literature, only two previous cases of prenatal bilateral WT diagnosed during the prenatal period have been reported $(4,5)$. In the first case, the family chose to abort the fetus due to a de novo translocation $\mathrm{t}(7 ; 19)$ ( $111.2 ; \mathrm{q} 13.3)$ that suggested a syndromic disease, while in the second case, the newborn survived. In that case, during the prenatal period, a right renal mass was detected and the infant was delivered by cesarean section at 38 weeks to avoid rupture of the mass. The mass was removed by nephrectomy three days after the birth. Computed tomography and magnetic resonance imaging were performed to evaluate the left kidney which revealed a peri- and intralobar nephroblastoma. The infant was treated with vincristine and dactinomycin for one year with a good outcome. At the one year follow-up, the patient was asymptomatic with normal renal function, since no clinical or molecular features of syndromic WT were observed (5). The differential diagnosis of WT includes multicystic dysplastic kidney, mesoblastic nephroma, neuroblastoma, and teratoma, and it is necessary to confirm the pathology by histological examination (2,30-32).

In our case, the renal mass was not detected during the prenatal period, due to the fact that the abdomen was not evaluated in detail. Consequently, the health care providers were not prepared for the infant's severe clinical conditions, including hypotension due to tumor rupture and massive hemorrhage of the renal artery. These conditions were wrongly associated with a cardiac disease and the abdomen was never evaluated. During the autopsy, tumor masses were found in both kidneys, suggesting bilateral WT, as confirmed by histological examination. In summary, based on this case, we conclude that complete assessment of the abdomen with ultrasonography and Ecocolor Doppler is needed to achieve a prenatal diagnosis of neonatal-onset WT. If a prenatal diagnosis had been made, the family would have received appropriate genetic counseling and would have been able to make a decision regarding whether to terminate the pregnancy. Moreover, this would have allowed the health care providers to be more prepared to manage the disease and its symptoms immediately after the birth.

\section{Conclusion}

This case suggests that a correct prenatal diagnosis is crucial to better manage this disease, as cases of newborns with WT who have survived have been described. Complete assessment of the abdomen with ultrasonography and Ecocolor Doppler can reveal kidney anomalies and raise suspicion of diseases with urinary malformations.

\section{Authors' contribution}

All authors read and approved the final manuscript. AS, MG and SG contributed to references update and 
manuscript final editing. DS and $\mathrm{CB}$ gave advise on the work and helped in the interpretation of the data. GDB, $\mathrm{AL}$ and GG planned the study design, supervised all the work and wrote the paper.

\section{Conflicts of interests}

The authors declare that they have no competing interests.

\section{Ethical considerations}

The research was conducted ethically in accordance with the World Medical Association Declaration of Helsinki. Written consent was obtained by parents and a copy is available for the journal. Parents have given consent to publish the case (including publication of figures).

\section{Funding/Support}

No funding was obtained for this study.

\section{References}

1. Szychot E, Apps J, Pritchard-Jones K. Wilms' tumor: biology, diagnosis and treatment. Transl Pediatr. 2014;3:1224. doi: 10.3978/j.issn.2224-4336.2014.01.09.

2. Dome JS, Huff V. Wilms Tumor Predisposition. In: Adam MP, Ardinger HH, Pagon RA, Wallace SE, Bean LJH, Stephens K, et al, eds. GeneReviews(R). Seattle (WA): University of Washington, Seattle University of Washington, Seattle; 1993.

3. Ritchey ML, Azizkhan RG, Beckwith JB, Hrabovsky EE, Haase GM.Neonatal Wilms tumor. J Pediatr Surg. 1995;30:856-859. doi: 10.1016/0022-3468(95)90764-5.

4. Cavicchioni O, Gomes DM, Leroy B, Vialard F, Hillion Y, Selva J, et al. Prenatal diagnosis of de novo $(7 ; 19)$ (q11.2;q13.3) translocation associated with a thick corpus callosum and Wilms tumor of the kidneys. Prenat Diagn. 2005;25:876-878. doi: 10.1002/pd.1129.

5. Linam LE, Yu X, Calvo-Garcia MA, Rubio EI, Crombleholme $\mathrm{TM}$, Bove K, et al. Contribution of magnetic resonance imaging to prenatal differential diagnosis of renal tumors: report of two cases and review of the literature. Fetal Diagn Ther. 2010;28:100-8. doi:10.1159/000313655.

6. Toma P, Lucigrai G, Dodero P, Lituania M. Prenatal detection of an abdominal mass by MR imaging performed while the fetus is immobilized with pancuronium bromide. AJR Am J Roentgenol. 1990;154:1049-50. doi: 10.2214/ ajr.154.5.2157328.

7. de Oliveira-Filho AG, Carvalho MH, Sbragia-Neto L, Miranda ML, Bustorff-Silva JM, de Oliveira ER. Wilms tumor in a prenatally diagnosed multicystic kidney. J Urol. 1997;158:1926-1927.

8. Homsy YL, Anderson JH, Oudjhane K, Russo P. Wilms tumor and multicystic dysplastic kidney disease. J Urol. 1997; 158:2256-9.

9. Suresh I, Suresh S, Arumugam R, Govindarajan M, Reddy MP, Sulochana NV. Antenatal diagnosis of Wilms tumor. J Ultrasound Med. 1997;16:69-72.

10. Applegate KE, Ghei M, Perez-Atayde AR. Prenatal detection of a Wilms' tumor. Pediatr Radiol. 1999;29:65-67.

11. Glick RD, Hicks MJ, Nuchtern JG, Wesson DE, Olutoye OO, Cass DL. Renal tumors in infants less than 6 months of age. J Pediatr Surg. 2004;39:522-5.

12. Vadeyar S, Ramsay M, James D, O'Neill D. Prenatal diagnosis of congenital Wilms' tumor (nephroblastoma) presenting as fetal hydrops. Ultrasound Obstet Gynecol. 2000;16:80-3. doi: 10.1046/j.1469-0705.2000.00169.x.

13. Jain V, Mohta A, Sengar M, Khurana N. Is antenatal detection of Wilms' tumor a bad prognostic marker?. Indian J Med Paediatr Oncol. 2011;32:214-6. doi : 10.4103/09715851.95144.

14. Segers H, van den Heuvel-Eibrink MM, Pritchard-Jones K, Coppes MJ, Aitchison M, Bergeron C, et al. Management of adults with Wilms' tumor: recommendations based on international consensus. Expert Rev Anticancer Ther. 2011;11:1105-13. doi: 10.1586/era.11.76.

15. Malogolowkin M, Spreafico F, Dome JS, van Tinteren H, Pritchard-Jones K, van den Heuvel-Eibrink MM,et al. Incidence and outcomes of patients with late recurrence of Wilms' tumor. Pediatr Blood Cancer. 2013;60:1612-5. doi: $10.1002 /$ pbc. 24604 .

16. Kembhavi SA, Qureshi S, Vora T, Chinnaswamy G, Laskar S, Ramadwar M,et al. Understanding the principles in management of Wilms' tumour: can imaging assist in patient selection? Clin Radiol. 2013;68:646-53. doi: 10.1016/j.crad.2012.11.012.

17. Sakai K, Shimodaira S, Maejima S, Udagawa N, Sano K, Higuchi $\mathrm{Y}$,et al. Dendritic cell-based immunotherapy targeting Wilms' tumor 1 in patients with recurrent malignant glioma. J Neurosurg. 2015;123:989-97. doi: 10.3171/2015.1.JNS141554.

18. Routh JC, Grundy PE, Anderson JR, Retik AB, Kurek KC. B7-h1 as a biomarker for therapy failure in patients with favorable histology Wilms tumor. J Urol. 2013;189:1487-92. doi: 10.1016/j.juro.2012.11.012.

19. Lodola F, Laforenza U, Bonetti E, Lim D, Dragoni S, Bottino $\mathrm{C}$, et al. Store-operated $\mathrm{Ca} 2+$ entry is remodelled and controls in vitro angiogenesis in endothelial progenitor cells isolated from tumoral patients. PLoS One. 2012;7:e42541. doi:10.1371/journal.pone.0042541.

20. Moccia F, Dragoni S, Lodola F, Bonetti E, Bottino C, Guerra $\mathrm{G}$, et al. Store-dependent $\mathrm{Ca}(2+)$ entry in endothelial progenitor cells as a perspective tool to enhance cell-based therapy and adverse tumour vascularization. Curr Med Chem. 2012;19:5802-18.

21. Dragoni S, Turin I, Laforenza U, Potenza DM, Bottino C, Glasnov TN, et al. Store-operated Ca2+ entry does not control proliferation in primary cultures of human metastatic renal cellular carcinoma. Biomed Res Int. 2014;2014:739494. doi: 10.1155/2014/739494.

22. Moccia F, Zuccolo E, Poletto V, Cinelli M, Bonetti E, Guerra G, et al. Endothelial progenitor cells support tumour growth and metastatisation: implications for the resistance to anti-angiogenic therapy. Tumour Biol. 2015;36:6603-14. doi: 10.1007/s13277-015-3823-2.

23. Zuccolo E, Bottino C, Diofano F, Poletto V, Codazzi A C, Mannarino S, et al. Constitutive store-operated $\mathrm{Ca}(2+)$ entry leads to enhanced nitric oxide production and proliferation in infantile hemangioma-derived endothelial colony-forming cells. Stem Cells Dev. 2016;25:301-19. doi: $10.1089 / \mathrm{scd} .2015 .0240$

24. Zuccolo E, Kheder DA, Lim D, Perna A, Nezza FD, Botta $\mathrm{L}$, et al. Glutamate triggers intracellular $\mathrm{Ca}(2+)$ oscillations 
and nitric oxide release by inducing NAADP- and InsP3 -dependent $\mathrm{Ca}(2+)$ release in mouse brain endothelial cells. J Cell Physiol. 2019 ;234:3538-3554. doi: 10.1002/jcp.26953.

25. Zuccolo E, Lim D, Kheder DA, Perna A, Catarsi P, Botta L,et al. Acetylcholine induces intracellular $\mathrm{Ca}(2+)$ oscillations and nitric oxide release in mouse brain endothelial cells. Cell Calcium. 2017;66:33-47. doi: 10.1016/j.ceca.2017.06.003.

26. Moccia F, Zuccolo E, Poletto V, Turin I, Guerra G, Pedrazzoli $\mathrm{P}$, et al. Targeting stim and orai proteins as an alternative approach in anticancer therapy. Current medicinal chemistry. 2016;23:3450-3480.

27. Zuccolo E, Laforenza U, Ferulli F, Pellavio G, Scarpellino G, Tanzi M, et al. Stim and Orai mediate constitutive $\mathrm{Ca}(2+)$ entry and control endoplasmic reticulum $\mathrm{Ca}(2+)$ refilling in primary cultures of colorectal carcinoma cells. Oncotarget. 2018;9:31098-31119. doi: 10.18632/oncotarget.25785.

28. Lodola F, Laforenza U, Cattaneo F, Alessandro Ruffinatti F, Poletto V, Massa M, et al. VEGF-induced intracellular $\mathrm{Ca}(2+)$ oscillations are down-regulated and do not stimulate angiogenesis in breast cancer-derived endothelial colony forming cells. Oncotarget. 2017;8:95223-95246. doi: 10.18632/oncotarget.20255.

29. Poletto V, Dragoni S, Lim D, Biggiogera M, Aronica A, Cinelli $\mathrm{M}$, et al. Endoplasmic reticulum $\mathrm{Ca} 2+$ handling and apoptotic resistance in tumor-derived endothelial colony forming cells. J Cell Biochem. 2016;117:2260-2271. doi:10.1002/jcb.25524.

30. Guerra G, Lucariello A, Perna A, Botta L, Luca AD, Moccia F. The role of endothelial $\mathrm{Ca}(2+)$ signaling in neurovascular coupling: a view from the lumen. Int J Mol Sci. 2018;19:938. doi: 10.3390/ijms19040938.

31. Moccia F, Lucariello A, Guerra G. TRPC3-mediated $\mathrm{Ca}(2+)$ signals as a promising strategy to boost therapeutic angiogenesis in failing hearts: The role of autologous endothelial colony forming cells. J Cell Physiol. 2018;233:3901-3917. doi: 10.1002/jcp.26152.

32. Baldi A, De Crescenzo V, Giordano DR, Lamberti R, Perna A, Picone C, et al. Cystic nephroma: report of a case and review of the literature. In Vivo. 2007;21:895-896.

Copyright (C) 2019 The Author(s); Published by Nickan Research Institute. This is an open-access article distributed under the terms of the Creative Commons Attribution License (http://creativecommons.org/licenses/by/4.0), which permits unrestricted use, distribution, and reproduction in any medium, provided the original work is properly cited. 